\title{
Speech therapy practice in hospital settings and COVID-19 pandemic
}

\author{
Drenda Carla Lima Araújo $0^{\mathbf{1}, 2}$ \\ Thales Rafael Correia de Melo Lima \\ (D) Vanessa Tavares de Gois-Santos 2,4 \\ (iD) Victor Santana Santos ${ }^{5}$ \\ Silvia de Magalhães Simões $e^{4,6}$ \\ (D) Paulo Ricardo Martins-Filho 2,4
}

\begin{abstract}
1. Departamento de Fonoaudiologia, Universidade Federal de Sergipe, Aracaju, SE, Brasil. 2. Laboratório de Patologia Investigativa, Universidade Federal de Sergipe, Aracaju, SE, Brasil. 3. Programa de Pós-Graduação Profissional em Gestão e Inovação Tecnológica em Saúde, Universidade Federal de Sergipe, Aracaju, SE, Brasil. 4. Programa de Pós-Graduação em Ciências da Saúde, Universidade Federal de Sergipe, Aracaju, SE, Brasil. 5. Centro de Epidemiologia e Saúde Pública, Universidade Federal de Alagoas, Arapiraca, SE, Brasil 6. Departamento de Medicina, Hospital Universitário/EBSERH, Universidade Federal de Sergipe, Aracaju, SE, Brasil.
\end{abstract}

http://dx.doi.org/10.1590/1806-9282.66.S2.10

KEYWORDS: Coronavirus infections. Speech therapy. Deglutition Disorders. Primary Health Care.

Dear editor,

Coronavirus disease 2019 (COVID-19), an emerging infectious disease caused by Severe Acute Respiratory Syndrome Coronavirus 2 (SARS-CoV-2), which is transmitted mainly by droplets and contact, has become a major health problem and resulted in new challenges for healthcare systems worldwide'. Multidisciplinary teams can play a major role in the management of patients with SARS-CoV-2 infections.

In the hospital setting, speech therapists must be involved in the care of patients with complaints and symptoms related to difficulty in swallowing, regardless of the underlying disease. It is necessary to reflect on the changes and challenges faced by these health professionals during the COVID-19 pandemic. The challenges with the emergence of COVID-19 include changes in the service schedule, work process, and the physical and organizational structure of the hospital environment.

Patients with severe symptoms associated with SARS-CoV-2 infections may require respiratory support, including endotracheal intubation and mechanical ventilation, and enteral nutrition by tube feeding. It has been reported that critically ill patients with COVID-19 can present severe muscle weakness, impaired mobility, neurological and psychological disorders, dysphagia, and smell and taste dysfunction ${ }^{2,3}$.

The speech therapy service aims to perform a clinical evaluation of swallowing to determine the risk 
of dysphagia and the safest diet route, in addition to defining the need for instrumental evaluation at the bedside. Preliminary results from a recent clinical study on the swallowing performance and safety of COVID-19 patients suggest fewer rehabilitation sessions to return to safe oral feeding when compared to critical Intensive Care Unit (ICU) patients without COVID-194.

The COVID-19 pandemic also caused limitations in conducting clinical evaluation, as the procedures performed by speech therapists require proximity to the patients' faces and contact with the oral mucosa and body fluids, such as saliva and respiratory droplets ${ }^{5}$. The available evidence recommends avoiding any type of stimulus that may trigger coughing and vomiting reflexes, including areas of the oral cavity, such as the base of the tongue, fauces, uvula, palate, and posterior pharynx wall ${ }^{6}$, in addition to restrictions on the use of cervical auscultation in the assessment of dysphagia ${ }^{7}$.

Instrumental assessment including video-fluoroscopy and endoscopic evaluation of swallowing should only be performed after patients test negative for SARS-CoV-2 infection in the previous 48 hours, but there are still controversies about the appropriate time to perform these procedures in the current context. Moreover, the recommendation is to avoid elective treatments since speech therapists are at high risk of contamination during aerosol-generating procedures ${ }^{8}$.

Biosafety modifications have been needed for speech therapy in the hospital setting. At present, particular attention has been paid to personal protective equipment (PPE), including the use of face masks and face shields, N95 respirators, eye protection, gloves, goggles, and disposable aprons ${ }^{9}$. Current evidence indicates that N95 respirators provide better protection than surgical masks in the laboratory environment and while aerosol-generating procedures, including speech therapy, coughing, aspiration of saliva or food, and management of tracheostomy. During the management of patients with COVID-19, speech therapists must also follow guidelines on social distancing and frequent handwashing to minimize the risk of infection.

An alternative for speech therapists is monitoring patients via a call center. However, there are still controversies in the literature about the effectiveness of this approach. A systematic review did not demonstrate the effectiveness of telerehabilitation in dysphagic patients compared to face-to-face therapy ${ }^{10}$. Other studies have found benefits in the call center approach, suggesting that it promotes increased access to clinical rehabilitation and guarantees adequate services for patients with swallowing disorders, requiring periods of intensive treatment followed by long-term management ${ }^{11-13}$. In the current scenario, call centers can be an alternative means of providing services, in a complementary way or replacing face-to-face treatments. The focus of speech therapists' work at this time should be to guide the implementation of a new flow of care, both for those hospitalized for other diseases, as well as for suspected cases of COVID-19, in addition to organizing the priority demand for cases of severe bronchoaspiration in dysphagic patients. One of the greatest challenges in the current and post-pandemic speech therapy practice is the difficulty in communicating with patients through expressions and gestures to demonstrate movements, which is impaired due to the use of PPE. Communication favors the professional-patient bond and is important for adherence to the treatment. However, for speech therapists who work in the hospital setting, reducing the risk of contamination and spreading the virus must be a team effort. Speech therapy in a hospital setting faced with this new respiratory virus should be based on rigorous biosafety measures and effective collaboration of professionals in the treatment of COVID-19 patients. Studies on the functional consequences of the disease are needed to understand possible sequelae and specific needs for speech therapists.

\section{Conflict of interest}

The authors have no conflict of interest to declare. Financial source: this study was not funded.

\section{Author's Contributions:}

All authors were involved in the drafting of the article or revised it critically for important intellectual content. All authors approved the final version to be submitted for publication as stated by the International Committee of Medical Journal Editors (ICMJE): Ms. Brenda Araújo had full access to all the data and the accuracy of the data analysis. ARAÚJO participated in the concept of the study, data collection, analysis and interpretation, and writing; LIMA, GOIS-SANTOS participated in data collection; SANTOS, SIMÕES AND MARTINS-FILHO participated in guiding, the concept of the study, analysis, interpretation of data, and writing 
PALAVRAS-CHAVE: Infecções por coronavírus. Fonoaudiologia. Transtornos de Deglutição. Atenção Primária à Saúde.

\section{REFERENCES}

1. Lin L, Lu L, Cao W, Li T. Hypothesis for potential pathogenesis of SARSCoV-2 infection: a review of immune changes in patients with viral pneumonia. Emerg Microbes Infect. 2020;9(1):727-32.

2. Kiekens C, Boldrini P, Andreoli A, Avesani R, Gamna F, Grandi M, et al. Rehabilitation and respiratory management in the acute and early postacute phase. "Instant paper from the field" on rehabilitation answers to the COVID-19 emergency. Eur J Phys Rehabil Med. 2020;56(3):323-6.

3. Lechien IR, Chiesa-Estomba CM, De Siati DR, Horoi M, Le Bon SD, Rodriguez $A$, et al. Olfactory and gustatory dysfunctions as a clinical presentation of mild-to-moderate forms of the coronavirus disease (COVID-19): a multicenter European study. Eur Arch Otorhinolaryngol. 2020;277(8):2251-61.

4. Lima MS, Sassi FC, Medeiros GC, Ritto AP, Andrade CRF. Preliminary results of a clinical study to evaluate the performance and safety of swallowing in critical patients with COVID-19. Clinics. 2020;75:e2021.

5. American Speech-Language-Hearing Association. SLP Service delivery considerations in health care during coronavirus/COVID-19. Rockville: American Speech-Language-Hearing Association; 2020. [cited 2020 Jun 13]. Available from: https://www.asha.org/SLP/healthcare/SLP-Service-Delivery-Considerations-in-Health-Care-During-Coronavirus/

6. Bolton L, Mills C, Wallace S, Brady MC, Royal College of Speech and Language Therapists (RCSLT) COVID-19 Advisory Group. Aerosol generating procedures, dysphagia assessment and COVID-19: a rapid review. Int J Lang Commun Disord. 2020;10.1111/1460-6984.12544.
7. Associação de Medicina Intensiva Brasileira. Parecer do Departamento de Fonoaudiologia da AMIB referente ao atendimento ao COVID-19 na terapia intensiva e no ambiente hospitalar. São Paulo: Associação de Medicina Intensiva Brasileira; 2020. [cited 2020 Jun 13]. Available from: https://www. amib.org.br/fileadmin/user_upload/amib/2020/marco/22/14_Parecer__ FonoaudiologiaCOVID-19.pdf

8. Jotz GP, Voegels RL, Bento RF. Otorhinolaryngologists and coronavirus disease 2019 (COVID-19). Int Arch Otorhinolaryngol. 2020;24(2):e125-8.

9. Sohrabi C, Alsafi Z, O'Neill N, Khan M, Kerwan A, Al-Jabir A, et al. Corrigendum to "World Health Organization declares global emergency: a review of the 2019 novel coronavirus (COVID-19)". Int J Surg. 2020;77:217.

10. Nordio S, Innocenti T, Agostini M, Meneghello F, Battel I. The efficacy of telerehabilitation in dysphagic patients: a systematic review. Acta Otorhinolaryngol Ital. 2018;38(2):79-85.

11. Morrell $K$, Hyers M, Stuchiner T, Lucas L, Schwartz K, Mako |, et al. Telehealth stroke dysphagia evaluation is safe and effective. Cerebrovasc Dis. 2017:44(3-4):225-31.

12. Tedesco A, Lavermicocca $V$, Notarnicola M, De Francesco L, Dellomonaco AR. Telemonitoring of swallowing function: technologies in speech therapy practice. Recenti Prog Med. 2018;109(2):146-8.

13. Mayadevi M, Thankappan K, Limbachiya SV, Vidhyadharan S, Villegas B, Ouyoung $M$, et al. Interdisciplinary telemedicine in the management of dysphagia in head and neck. Dysphagia. 2018;33(4):474-80. 